\title{
Absorption and mobility of foliar-applied boron in soybean as affected by plant boron status and application as a polyol complex
}

\author{
Silke Will • Thomas Eichert • Victoria Fernández • \\ Jens Möhring • Torsten Müller • Volker Römheld
}

\begin{abstract}
In the present study (i) the impact of plant Boron (B) status on foliar B absorption and (ii) the effect of $\mathrm{B}$ complexation with polyols (sorbitol or mannitol) on B absorption and translocation was investigated. Soybean (Glycine max (L.) Meer.) plants grown in nutrient solution containing $0 \mu M, 10 \mu M$, $30 \mu M$ or $100 \mu M^{11} \mathrm{~B}$ labelled boric acid (BA) were treated with $50 \mathrm{mM}{ }^{10} \mathrm{~B}$ labelled $\mathrm{BA}$ applied to the basal parts of two leaflets of one leaf, either pure or in
\end{abstract}

\section{S. Will $(\bowtie) \cdot$ T. Müller $\cdot$ V. Römheld}

Institute of Crop Science, Plant Nutrition Unit,

Universität Hohenheim,

Fruwirthstraße 20,

70593 Stuttgart, Germany

e-mail: Silke.will@uni-hohenheim.de

T. Eichert

Plant Nutrition Department,

Institute of Crop Science and Resource Conservation,

University of Bonn,

Karlrobert-Kreiten-Str. 13,

53115 Bonn, Germany

V. Fernández

Plant Nutrition Department, Aula Dei Experimental

Station, CSIC,

P.O. Box 13034, 50080 Zaragoza, Spain

J. Möhring

Institute of Crop Science, Bioinformatics Unit,

Universität Hohenheim,

Fruwirthstraße 23,

70593 Stuttgart, Germany combination with $500 \mathrm{~m} M$ sorbitol or mannitol. After one week, ${ }^{10} \mathrm{~B}$ concentrations in different plant parts were determined. In B deficient leaves $\left(0 \mu M^{11} \mathrm{~B}\right),{ }^{10} \mathrm{~B}$ absorption was significantly lower than in all other treatments $(9.7 \%$ of the applied dose vs. $26 \%-32 \%)$. The application of BA in combination with polyols increased absorption by $18-25 \%$ as compared to pure BA. The absolute amount of applied ${ }^{10} \mathrm{~B}$ moving out of the application zone was lowest in plants with $0 \mu M$ ${ }^{11} \mathrm{~B}$ supply $(1.1 \%$ of the applied dose $)$ and highest in those grown in $100 \mu M^{11} \mathrm{~B}(2.8 \%)$. The presence of sorbitol significantly decreased the share of mobile ${ }^{10} \mathrm{~B}$ in relation to the amount absorbed. The results suggest that ${ }^{11} \mathrm{~B}$ deficiency reduces the permeability of the leaf surface for BA. The addition of polyols may increase ${ }^{10} \mathrm{~B}$ absorption, but did not improve ${ }^{10} \mathrm{~B}$ distribution within the plant, which was even hindered when applied a sorbitol complex.

Keywords B deficiency $\cdot$ B toxicity $\cdot$ Foliar absorption · Mannitol · Sorbitol · Soybean · Water potential

\section{Introduction}

Warrington (1923) proved boron (B) to be an essential micronutrient for higher plants. Even though the demand for B on a molar basis is higher than for any other micronutrient in dicotyledons, knowledge of its physiological role is still limited. Boron 
deficiency appears worldwide in crop production and is reported in over 80 countries on 132 crops. The occurrence of $\mathrm{B}$ deficiency depends on multiple factors, such as e.g. weather conditions (drought, high precipitation, etc.), soil conditions (low $\mathrm{pH}$ soils B leaching, calcareous soils B fixation) and the cultivated crop species (Shorrocks 1997). Physiological responses of plants to $\mathrm{B}$ deficiency include the loss of membrane integrity and cell wall stability, which result in the development of structural damage in crop plants like for instance, cracked stem in celery, stalk rot in cauliflower, heart rot and internal black spot in beet, top rot in tobacco and internal cork in apple (Blevins and Lukaszewski 1998). Several studies showed that B deficiency induces leaf structural changes, including abnormal stomata and distorted guard cells in cauliflower (Sharma and Sharma 1987) and coffee (Rosolem and Leite 2007) or decreased stomatal conductance and transpiration rates in navel orange and cotton (Oosterhuis and Zhao 2001; Sheng et al. 2009). Many other effects associated with $\mathrm{B}$ imbalances have been described, but the direct role of $\mathrm{B}$ in metabolism is still little understood.

In commercial plant production, providing a sufficient B supply is particularly important for yield formation (pollination) (Khayyat et al. 2007; Wojcik et al. 1999), fruit quality and crop storability (Wojcik et al. 1999), and stress tolerance (Cakmak and Römheld 1997). In addition to B deficiency, B toxicity can also considerably limit plant production (Miwa et al. 2006). Natural B toxicity occurs in soils in arid and semi-arid environments or may derive from mining deposits, fertilizers or irrigation water. Information available on B toxicity is fragmentary (Nable et al. 1997). Brown and Hu (1996) described symptoms of toxicity such as the death of cambial tissues and stem die back, causing fruit disorders (gummy nuts, internal necrosis) and bark necrosis. A loss in membrane integrity in association with B toxicity was reported by Alpaslan and Gunes (2001).

In most plant species, B is phloem immobile and distribution of $\mathrm{B}$ within a plant mainly follows the transpiration stream. The first visual effects of $B$ deficiency can be observed in young leaves and meristematic tissues, whereas B toxicity symptoms are mainly visible in older leaves especially in the leaf tips where the transpiration stream ends (Poss et al. 1999).
Within the cell wall and cytoplasm, B quickly forms stable complexes (mainly mono- and diesters) and contributes to the water insoluble fraction. Thus, re-translocation from source to sink organs is not easily accomplished in the plant. In a wide range of plants, sugar alcohols (also called polyhydric alcohols or polyols) are present in the phloem sap. Most common are the straight-chained hexiols such as mannitol and sorbitol (Bieleski 2005). They contain cis-diol groups which can form stable complexes with B. These compounds facilitate the re-translocation from old leaves to "sink" organs such as young developing leaves, roots, fruits and meristematic tissues (Brown and $\mathrm{Hu}$ 1996; Brown et al. 1999; Delgado et al. 1994; Shelp et al. 1998). Boron mobility was evidenced in plants mainly belonging to the Rosaceae family (e.g., apple, cherry, peach) having large quantities of the sugar-alcohol sorbitol in the phloem sap, and also in those rich in mannitol largely corresponding to the families of Apiaceae (carrots and celery), Brassicaceae (broccoli, cauliflower), Fabaceae (pea, common bean) and Oleaceae (olive) (Bieleski 1982; Brown and Shelp 1997). Blevins and Lukaszewski (1998) found a large quantity of the sugar alcohol pinitol in the phloem sap of soybean, but the possibility of complex formation with $\mathrm{B}$ and re-translocation remains unclear (Bieleski 2005). Lehto et al. (2004) suggested a possible role of $\mathrm{B}$ complex formation with inositol or pinitol in Scots pine (Pinus sylvestris L.) and Norway spruce (Picea abies (L.) H. Karst), but stable complexes could not be directly demonstrated.

In the present study the impact of plant B status on B foliar absorption and the effect of B complex application on improving absorption and translocation was investigated in soybean. Some experiments carried out with soybean cultivar "Oak Erin" suggested that pinitol (i.e. the polyol detected in soybean) does not significantly contribute to B mobility. In contrast to sorbitol and mannitol, pinitol is a cyclic polyol. Since the process of complex formation between $\mathrm{B}$ and pinitol remains unclear, it was not investigated as a candidate for foliar $\mathrm{B}$ application trials.

Thereby, to assess the effect of B complex application, sorbitol and mannitol were selected since stable B complexes with these compounds have been previously reported $(\mathrm{Hu}$ and Brown, 1997). In preliminary trials (data not shown) a 1:10 B:sorbitol ratio was found to increase the rate of foliar $B$ 
absorption and translocation in soybean plants. Hence, the following two hypotheses were tested, namely: (i) plant B status may affect the absorption and the within-plant mobility of foliar-applied B and (ii) foliar application of B-sorbitol and B-mannitol complexes can increase absorption and the withinplant mobility of B.

\section{Material and methods}

Pre-treatment

Soybean seeds (Glycine max (L.) Meer., cv. "Oak Erin") were soaked for $1 \mathrm{~h} \mathrm{in} 10 \mathrm{mMCaSO}$ solution and then transferred to filter paper moistened with $2.5 \mathrm{mM}$ $\mathrm{CaSO}_{4}$ until radicles emerged. Seedlings were planted into 31 plastic pots (4 plants per pot) containing continuously aerated nutrient solution $(\mathrm{pH} 5.5)$ of the following composition: $0.88 \mathrm{mM} \mathrm{K}_{2} \mathrm{SO}_{4}, 0.1 \mathrm{mM} \mathrm{KCl}$, $2 \mathrm{~m} M \mathrm{Ca}\left(\mathrm{NO}_{3}\right)_{2}, 1 \mathrm{~m} M \mathrm{MgSO}_{4}, 0.25 \mathrm{~m} M \mathrm{KH}_{2} \mathrm{PO}_{4}$, $10 \mu M{ }^{11} \mathrm{~B}(\mathrm{OH})_{3}$ (enrichment 99.8\%), $0.5 \mu M \mathrm{MnSO}_{4}$, $0.2 \mu M \mathrm{CuSO}_{4}, 0.02 \mu M\left(\mathrm{NH}_{4}\right)_{6} \mathrm{Mo}_{7} \mathrm{O}_{24}, 1 \mu M \mathrm{ZnSO}_{4}$ and $100 \mu M \mathrm{Fe}$ (III)EDTA. The nutrient solution was prepared with de-ionized water and changed on a weekly basis. Plants were cultivated in a climate chamber (Universität Hohenheim, Germany) with a radiation of approximately $1000 \mu \mathrm{mol} \mathrm{m} \mathrm{m}^{-2}$. Day $(14 \mathrm{~h})$ and night $(10 \mathrm{~h})$ temperatures were kept at 24 and $20^{\circ} \mathrm{C}$ respectively, with a relative humidity $(\mathrm{RH})$ of $60 \%$. After cultivation in full-strength nutrient solution for 2 weeks, the 16 pots were divided into 4 groups which were consequently supplied for 2 weeks with a nutrient solution containing $0 \mu M, 10 \mu M, 30 \mu M$ or $100 \mu M^{11} \mathrm{~B}$-labelled BA,

Foliar formulations

Foliar treatment solutions were prepared with a basic de-ionized water solution containing $50 \mathrm{mM}$ ${ }^{10} \mathrm{~B}$ labelled boric acid (BA) plus $0.5 \%(\mathrm{v} / \mathrm{v})$ surfactant (Plantacare, Cognis, Düsseldorf). Sorbitol and mannitol were used at a concentration of $500 \mathrm{mM}$, because concentrations of $\mathrm{B}$ and sorbitol in ratio 1:10 facilitates the formation of 1:2 B-polyol complexes (Hu and Brown 1997). The basic solution (BaSol) was used as the control in order to compare whether the polyols contribute to the quantitative absorption and/or affect the within-plant mobility of absorbed B. Treatments of the experiment were as follows:

1. Boron (B): Basic solution (BaSol)

2. Mannitol (BM): BaSol with B:mannitol ratio 1:10 (w/w)

3. Sorbitol (BS): BaSol with B:sorbitol ratio 1:10 (w/w)

All chemicals were of analytical grade (Merck, Darmstadt, Germany).

Data collection and sampling design

Data were collected from 16 pots containing 4 plants per pot, in total 64 plants. The pots were set using a split plot design with 4 replicates. The main plot factor pre-treatment has 4 levels: nutrient solutions with $0,10,30$, and $100 \mu M{ }^{11} \mathrm{~B}$ concentration, the sub plot factor foliar formulation has three levels: basic solution, basic solution with sorbitol and basic solution with mannitol. The fourth plant within each pot was used to measure the water potential.

\section{Application}

Foliar treatment solutions were applied on leaflets of the last fully-expanded leaves. Treatments were supplied via application of $16^{*} 2.5 \mu 1$ drops ( $40 \mu \mathrm{l}$ in total) of the formulation on two adjacent leaflets per leaf. Soybean leaves consist of three leaflets, two are paired and one is the upper leaflet. Drops were applied to the lower half of the paired leaflets (Fig. 1). Leaves were harvested after 1 week and separated into segments. Distribution of

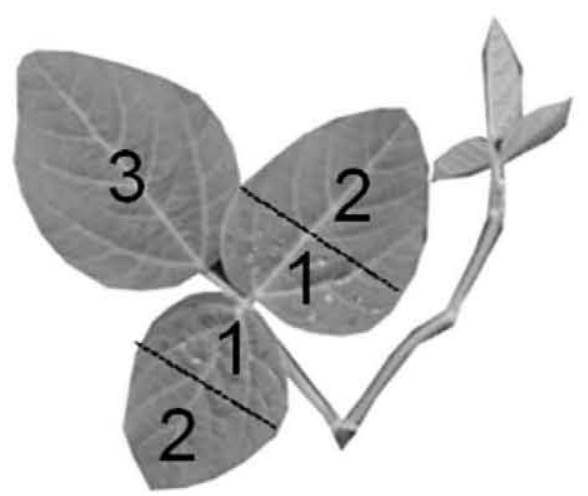

Fig. 1 Schematic presentation of soybean leaf segments used for the analysis of B absorption and translocation. 1: application zone (lower part of a leaflet), 2: leaf tip, 3: non-treated leaflet of a treated leaf 
the applied ${ }^{10} \mathrm{~B}$ was separately determined for the different segments as indicated in Fig. 1.: Segment 1: fraction remaining in the application zone, segment 2 : fraction of ${ }^{10} \mathrm{~B}$ in the leaf tip indicating acropetal translocation via transpiration stream and segment 3 : fraction in non-treated leaflets of the treated leaf indicating short distance basipetal translocation via phloem. All samples from segment 1 were carefully rubbed under de-ionized water between gloved thumb and forefinger for 20 seconds to remove trapped material (Eichert and Goldbach 2008).

\section{Analytical methods}

Harvested leaves were dried in the oven at $65^{\circ} \mathrm{C}$ for 2 days. Ground dry leaf samples $(0.05-0.1 \mathrm{~g})$ were weighed in quartz crucibles. The samples were ashed in the oven with increasing temperatures $\left(200^{\circ} \mathrm{C}, 300^{\circ} \mathrm{C}\right.$, $400^{\circ} \mathrm{C}$ and $500^{\circ} \mathrm{C}$ for $1,1,1$ and 2 hours, respectively) then samples were cooled down overnight. Next day, samples were rewetted with some drops of $3 \% \mathrm{H}_{2} \mathrm{O}_{2}$ solution and after drying, ashed again in the oven for 3 hours at $500^{\circ} \mathrm{C}$. The ash was dissolved in $5 \mathrm{ml}$ mixed acid solution $\left[3.3 \% \mathrm{v} / \mathrm{v} \quad \mathrm{HNO}_{3}+10 \mathrm{ppb}\right.$ Beryllium (Be)] and centrifuged for 2 minutes at $4000 \times \mathrm{g}$ (Hettich Universal $30 \mathrm{~F})$. Boron isotopes $\left({ }^{10} \mathrm{~B},{ }^{11} \mathrm{~B}\right)$ were determined by inductively coupled plasma mass spectroscopy (ICP-MS, ELAN 6000, Perkin-Elmer, Überlingen, Germany), using $\mathrm{Be}$ as an internal standard. B concentrations and contents in each segment were calculated.

\section{Water potential}

Leaf water potentials were measured using the Scholander pressure chamber method (Scholander et al. 1965). From each pot one plant was randomly selected $(n=4)$, the last fully-developed leaves of soybean plants were harvested and immediately fixed into the Scholander pressure chamber. For standardization of the moment when the xylem fluid appeared, tissue paper was held carefully on the top of the leaf stem. As soon as a liquid drop was visually observed, the pressure was recorded. This method was implemented to facilitate the visual detection of the sap appearance, since in former experiences with drought stressed plants, only small and disperse drops similar to foam could be seen to come out of the soybean leaf petiole.
Scanning electron microscopy (SEM) examination

Leaf surfaces were examined under a scanning electron microscope (S- 3400N, Hitachi, Tokyo, Japan; acceleration potential $15 \mathrm{kV}$, working distance $10-11 \mathrm{~mm}$ ). Leaves from the different treatments were dried at room temperature, making sure that the surface remained flat. For observation of either the upper or lower leaf side, approximately $1 \mathrm{~cm}^{2}$ sections were excised, and sputtered with gold. Different areas of the leaf sections were subsequently directly observed under the microscope. The abaxial and adaxial surface of five leaves was examined for each treatment. The length and width of stomatal pores $(n=100)$ was assessed by the programme Image-Pro Plus 6 (Bethesda, USA)

Statistics

A mixed model approach was used for statistical analysis. For fixed effects general least square means were estimated and presented with their standard error in the results. An univariate analysis was performed for the ${ }^{10} \mathrm{~B}$ concentration of each segment, the sum of segments 2 and 3 , the propotion of ${ }^{10} \mathrm{~B}$ in segment 2 or 3 compared to all segments, for the water potential and the ${ }^{11} \mathrm{~B}$ concentration. A multivariate analysis was used for a combined analysis of ${ }^{10} \mathrm{~B}$ over all segments. In addition, the water potential und the ${ }^{11} \mathrm{~B}$ concentration were used as covariates for ${ }^{10} \mathrm{~B}$, but were dropped from the model as they had no significant influence.

To reach homogeneous residual variation for univariate and multivariate analysis, the data were logarithmically transformed for the traits ${ }^{10} \mathrm{~B}$ and ${ }^{11} \mathrm{~B}$. For analysing the proportions of segment 2 or 3 the ${ }^{10} \mathrm{~B}$ data were transformed using the logit as link function. In both cases estimated means were back transformed for presentation. The shown standard errors of these means were back transformed using the delta method.

The model for the univariate analysis is given by:

$y_{i j k l m}=\mu+r_{k}+\alpha_{i}+\beta_{j}+(\alpha \beta)_{i j}+p_{k l}+e_{i j k l m}$,

where $r_{k}$ is the effect for the $k^{\text {th }}$ replicate, $p_{k l}$ is the main plot error effect of the $l^{\text {th }}$ pot in the $k^{\text {th }}$ replicate, $\alpha_{i}$ is the $i^{\text {th }}$ pre-treatment effect and $\beta_{j}$ is the $j^{\text {th }}$ nutrient solution effect. $(\alpha \beta)_{i j}$ denotes the interaction 
effect of the $i^{\text {th }}$ pre-treatment and the $j^{\text {th }}$ nutrient solution. $e_{i j k l m}$ denotes the subplot error or residual error effect of the $i^{\text {th }}$ pre-treatment, $j^{\text {th }}$ nutrient solution of the $m^{\text {th }}$ plant in the $l^{\text {th }}$ pot in the $k^{\text {th }}$ replicate. All factors and interactions were taken as fixed. The main and sub plot error were taken as random. The replicate effect was treated as fixed ignoring all inter block information.

For the multivariate analyses the model is given by:

$$
\begin{aligned}
y_{i j k l m n}= & \mu+r_{k n}+\alpha_{i}+\beta_{j}+(\alpha \beta)_{i j}+(\alpha \gamma)_{i n} \\
& +(\beta \gamma)_{j n}+(\alpha \beta \gamma)_{i j n}+p_{k l n}+e_{i j k l m n},
\end{aligned}
$$

where $\gamma_{n}$ denotes the $n^{\text {th }}$ segment, and interactions and all other effects are denotes as in equation (1). For the pot effects $p_{k I n}$ of the three segments and for the residual error effects $e_{i j k l m n}$ of the three segments an unstructered variance-covariance matrix was assumed a priori. Because of small or fixed main plot variance component estimates the variance-covariance structure for the analysis of ${ }^{10} \mathrm{~B}$ was simplified by dropping the covariances between main plot effects of one plant. Thus the optimal variance-covariance structure included heterogeneous variances for segments but no covariances. An Akaike Information Criterion (AIC) (Akaike, 1974) based model selection approach was used to find this model.

\section{Results}

\section{Plant B status}

Growth of soybean plants under various isotopicallylabelled BA concentrations in the nutrient solution resulted in plants with different ${ }^{11} \mathrm{~B}$ tissue concentrations. Plants grown in full-strength nutrient solution with $0,10,30$ or $100 \mu M^{11} \mathrm{~B}$ had average ${ }^{11} \mathrm{~B}$ tissue concentrations of $2.1( \pm 0.2), 50.9( \pm 5.2), 86.7( \pm 8.9)$ and $103.7( \pm 10.7) \mu \mathrm{g}^{11} \mathrm{~B} \mathrm{~g}^{-1} \mathrm{DW}$, respectively.

\section{Visual symptoms}

Symptoms were observed in plants with $0 \mu M^{11} \mathrm{~B}$ and $100 \mu M{ }^{11} \mathrm{~B}$ supply. Plants grown without ${ }^{11} \mathrm{~B}$ showed deficiency symptoms such as diminished root and shoot growth. Root development was significantly decreased in plants without ${ }^{11} \mathrm{~B}$ supply in compar- ison to plants treated with 10,30 or $100 \mu M{ }^{11} \mathrm{~B}$ $(1.4 \pm 0.1,4.6 \pm 0.9,5.3 \pm 0.5,4.8 \pm 0.4 \mathrm{~g}$ dry weight, respectively). Roots were brownish in colour and shoot development was decelerated, due to the dying off of apical meristems. Leaves became very hairy, rigid, dark green, small and interveinal necrosis appeared. The inclination of the leaves was abnormal. They grew vertical and leaf tips pointed downwards. Moreover, alterations in the surface morphology of leaves in plants with $0 \mu M{ }^{11} \mathrm{~B}$ were observed. Stomata appeared closed, collapsed and sunken underneath the epidermis (Fig. 2). Whereas the pore lengths of $\mathrm{B}$ deficient leaves did not differ from leaves grown under adequate $\left(10 \mu M^{11} \mathrm{~B}\right) \mathrm{B}$ supply (-B: $8.4 \pm 1.3 \mu \mathrm{m},+\mathrm{B}: 8.5 \pm 1.3 \mu \mathrm{m}, n=100$ ), the pore widths differed significantly. In $B$ deficient leaves average pore widths were $0.1 \pm 0.3 \mu \mathrm{m}$, while with adequate B supply widths were $3.2 \pm 1.3 \mu \mathrm{m}(n=100)$.

Abnormal leaf inclinations were also observed in association with $100 \mu M^{11} \mathrm{~B}$ supply. Furthermore, older leaves were also rigid and showed veinal browning on the lower leaf surface, with black spots on the upper leaf surface. In all treatments, the dry matters of the treated leaves varied between 300 to $400 \mathrm{mg}$ and no clear trend could be detected in association with the different B regimes. Development and phenology of roots and shoots of plants with $10 \mu M{ }^{11} \mathrm{~B}$ and $30 \mu M{ }^{11} \mathrm{~B}$ supply was in accordance to normal growth of the species.

Necrotic spots appeared beneath the applied droplets in some of the treatments. The degree of damage depended on the composition of the formulations and the plant ${ }^{11} \mathrm{~B}$ status. Regardless of the foliar formulations applied to the B-deficient plants $\left(0 \mu M^{11} \mathrm{~B}\right)$ necrotic spots never developed on the treated leaf areas. Increased phytotoxicity symptoms were observed in plants cultivated in 30 and $100 \mu M^{11} \mathrm{~B}$. The degree of damage was most severe after the application of formulations containing sorbitol.

Water status

Water potential $\left(\psi_{\mathrm{w}}\right)$ measurements showed highest values of $-0.59 \pm 0.05 \mathrm{MPa}$ and $-0,61 \pm 0.06 \mathrm{MPa}$ in plants with $0 \mu M^{11} \mathrm{~B}$ and $100 \mu M^{11} \mathrm{~B}$ supply, respectively. In plants with $10 \mu M^{11} \mathrm{~B}$ and $30 \mu M^{11} \mathrm{~B}$ supply, $\psi_{\mathrm{w}}$ was lower with values of $-0.78 \pm$ $0.13 \mathrm{MPa}$ and $-0.74 \pm 0.12 \mathrm{MPa}$, respectively. 
Fig. 2 SEM micrographs of the abaxial leaf surface of soybean leaves. Stomata appeared closed, collapsed and sunken underneath the epidermis on plants grown without ${ }^{11} \mathrm{~B}(\mathbf{a}, \mathbf{c})$ and developed regularly on plants treated with $10 \mu M^{11} \mathrm{~B}$ in the nutrient solution $(\mathbf{b}, \mathbf{d})$
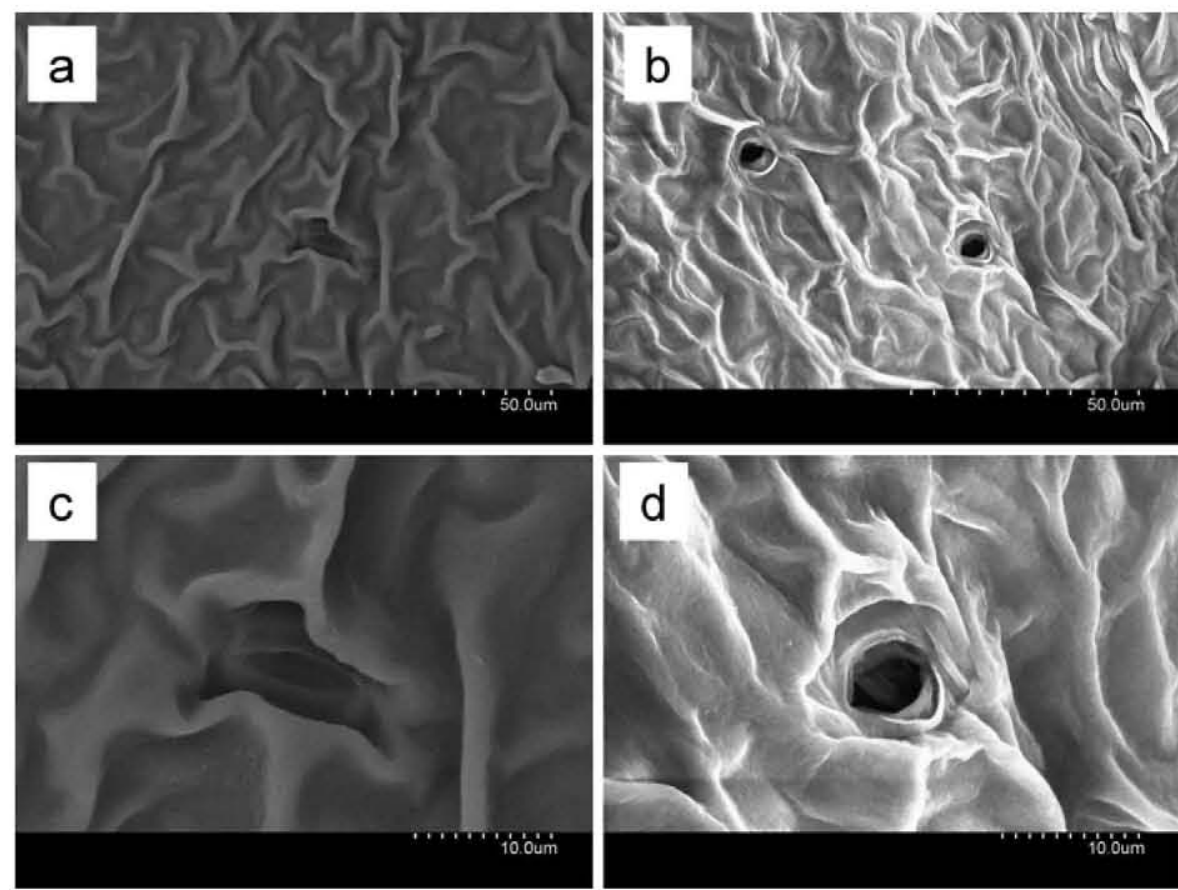

Absorption and mobility

Both B absorption and B translocation were significantly affected by plant ${ }^{11} \mathrm{~B}$ status and the addition of polyols, whereas interactions between these 2 factors were not significant (Table 1). When applied as pure BA $18.2 \%$ of the foliar-applied ${ }^{10} \mathrm{~B}$ was absorbed by the leaves, while with the addition of sorbitol or mannitol the proportion of absorbed ${ }^{10} \mathrm{~B}$ increased to $22.9 \%$ and $25.4 \%$, respectively (Fig. 3a). Plants with $0 \mu M{ }^{11} \mathrm{~B}$ supply showed the lowest ${ }^{10} \mathrm{~B}$ contents representing only $9.7 \%$ of the applied dose, whereas in the other treatments $26.5 \%$ to $32.3 \%$ of the applied ${ }^{10} \mathrm{~B}$ penetrated the leaf surfaces (Fig. 3b).

Table 1 Results of statistical analysis of ${ }^{10} \mathrm{~B}$ contents in segments 1 (application zone), 2 (upper part of treated leaf), and 3 (neighbouring leaflet) as affected by the ${ }^{11} \mathrm{~B}$ supply during pre-culture ("B status") and the foliar application as pure boric acid or boric acid in combination with polyols ("foliar treatment")

\begin{tabular}{lccc}
\hline Source of variation & Segment 1 & Segment 2 & Segment 3 \\
\hline B status & $<0.001$ & $<0.001$ & 0.0005 \\
Foliar treatment & 0.0038 & 0.0045 & 0.0253 \\
Interaction & 0.4901 & 0.3671 & 0.4829 \\
\hline
\end{tabular}

The share of mobile ${ }^{10} \mathrm{~B}$ which moved out of the application zone towards the tips of the treated leaves and the adjacent leaflet ranged from $1.1 \%$ to $2.8 \%$ of the applied dose (Fig. 3d). It was lowest in plants with $0 \mu M{ }^{11} \mathrm{~B}$ supply and overall highest in the plants grown under $100 \mu M{ }^{11} \mathrm{~B}$ supply. The addition of mannitol did not significantly affect the share of applied ${ }^{10} \mathrm{~B}$ found in other plant parts, whereas sorbitol overall lead to a significant reduction in mobile foliar-applied ${ }^{10} \mathrm{~B}$ (Fig. 3c).

While the share of mobile ${ }^{10} \mathrm{~B}$ expressed as $\%$ of the applied ${ }^{10} \mathrm{~B}$ is important in practical terms, the significance of this parameter for the analysis of within-plant ${ }^{10} \mathrm{~B}$ mobility is rather limited, because it depends on both, the absorption process and the subsequent translocation in the plant. Therefore, we expressed the amounts of ${ }^{10} \mathrm{~B}$ detected in other plant

Fig. 3 Effect of polyols (a, c, e, g) and different ${ }^{11} \mathrm{~B}$ supply during growth $(\mathbf{b}, \mathbf{d}, \mathbf{f}, \mathbf{h})$ on foliar absorption of ${ }^{10} \mathrm{~B}(\mathbf{a}, \mathbf{b})$, total ${ }^{10} \mathrm{~B}$ translocation to the tips of the treated leaflets and neighbouring leaflets as percentage of the applied dose (c, d), and ${ }^{10} \mathrm{~B}$ translocation as percentage of absorbed $\mathrm{B}$ to tips of the treated leaflets $(\mathbf{e}, \mathbf{f})$ and neighbouring leaflets $(\mathbf{g}, \mathbf{h})$. Plants were treated either with $50 \mathrm{mM}{ }^{10} \mathrm{~B}$-labelled boric (B), $50 \mathrm{mM}$ labelled boric acid and $500 \mathrm{mM}$ sorbitol $(\mathrm{B}+$ sorbitol) or $50 \mathrm{mM}$ labelled boric acid and $500 \mathrm{mM}$ mannitol (B+mannitol). Error bars represent the standard errors of the means. Values marked by the same letter are not significantly different 

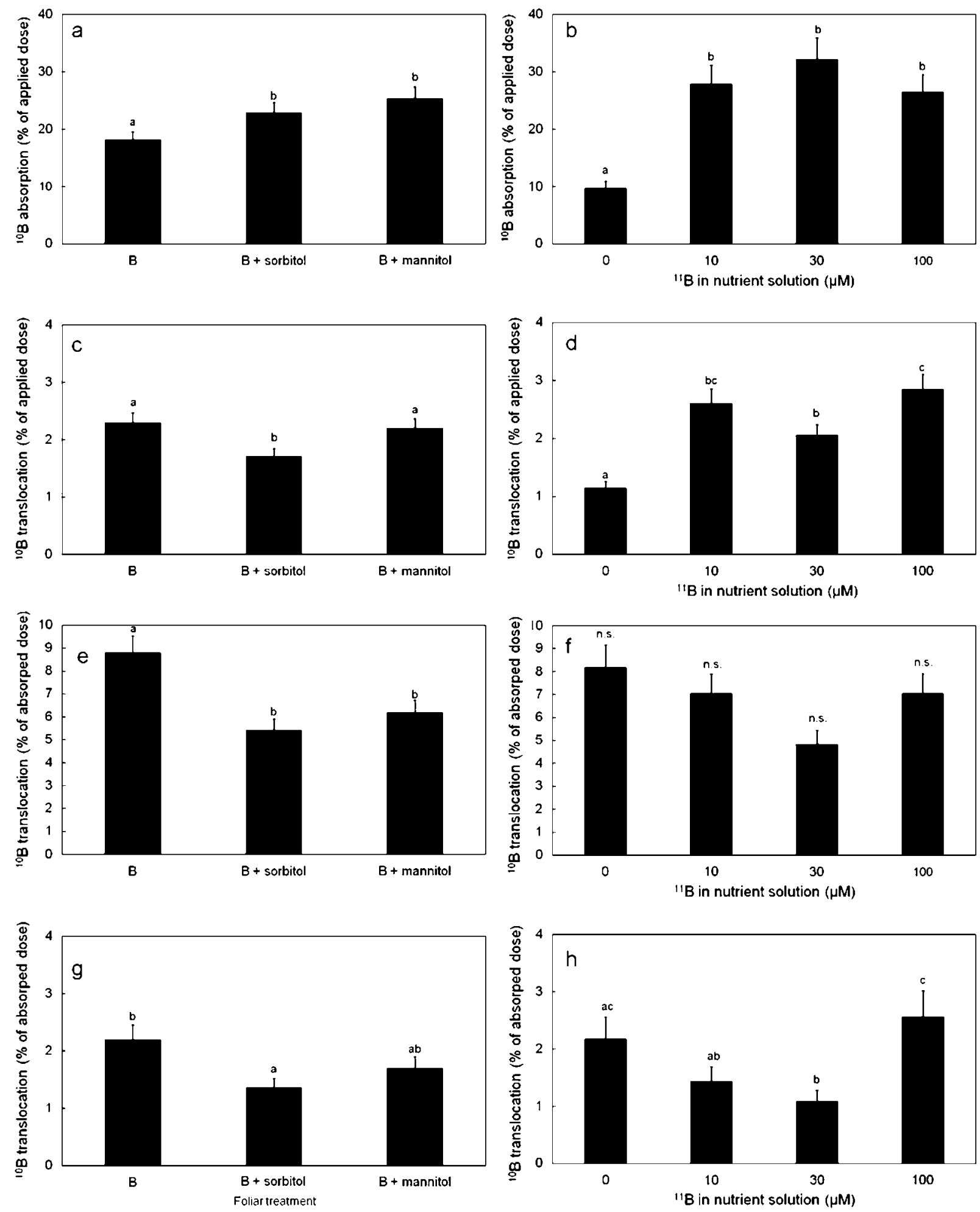
parts as $\%$ of the total amount that penetrated the leaves. The share of penetrated ${ }^{10} \mathrm{~B}$ that moved to the tips of the treated leaflets (segment 2, Fig. 1) was higher in plants with $0 \mu M^{11} \mathrm{~B}$ supply. In plants grown under $30 \mu M^{11} \mathrm{~B}$ the share of penetrated ${ }^{10} \mathrm{~B}$ was the lowest (Fig. 3f). The addition of both polyols significantly decreased ${ }^{10} \mathrm{~B}$ movement into the tips of the treated leaflets (Fig. 3e).

Similar effects were found in the neighbouring leaflet (segment 3). The highest shares of penetrated ${ }^{10} \mathrm{~B}$ were detected in plants grown in $0 \mu M{ }^{11} \mathrm{~B}$ or $100 \mu M^{11} \mathrm{~B}$ (Fig. $3 \mathrm{~h}$ ), and polyols decreased relative mobility (Fig. 3g).

B concentrations in other plant parts were below the detection limit of $1 \mu \mathrm{g} \mathrm{g}^{-1} \mathrm{DW}$. This assumption derives from former experiments where ${ }^{10} \mathrm{~B}$ measured in other plant parts were below the detection limit.

\section{Discussion}

Symptoms of different B root supply

Two weeks after the onset of the ${ }^{11} \mathrm{~B}$ treatments, plants showed different visual symptoms. The greatest effect was observed in plants grown without ${ }^{11} \mathrm{~B}$, indicating that they suffered from B deficiency. Shoots and roots showed a significant reduction in growth and development. Moreover, leaf surface morphology alterations were found in plants grown under ${ }^{11} \mathrm{~B}$ shortage. Stomata of $\mathrm{B}$-deficient leaves were closed, collapsed and sunken underneath the epidermis (Fig. 2). Several studies showed that B deficiency induced leaf structural changes including abnormal stomatal morphology and altered functionality (Oosterhuis and Zhao 2001; Rosolem and Leite 2007; Sharma and Sharma 1987; Sheng et al. 2009) but the underlying mechanisms of this physiological response to $B$ deficiency remain speculative.

Boron deficiency and B toxicity affect membrane permeability (Alpaslan and Gunes 2001; Cakmak et al. 1995), resulting in membrane leakage and as a consequence K-efflux. Potassium is particularly important for the osmotic regulation of stomatal aperture. Due to the possible $\mathrm{K}$ membrane leakage in $\mathrm{B}$-deficient or B -intoxicated plants this regulation could be dysfunctional, which may also explain the higher leaf water potentials at the lowest or highest B supply observed in this study. Another possible explanation for stomatal closure in B deficient plants could be the involvement of $B$ in the structure of the cell walls and microfibrilles of the guard cells enabling stomatal opening.

The cultivation of plants under $100 \mu M^{11} \mathrm{~B}$ in the nutrient solution induced toxicity symptoms affecting shoot but not root growth as observed visually and by measurement of the root dry mass. The shoots of plants treated with $100 \mu M^{11} \mathrm{~B}$ supply did not differ in size and development as compared to plants with $10 \mu M^{11} \mathrm{~B}$ and $30 \mu M^{11} \mathrm{~B}$ concentrations in the nutrient solution, but the oldest leaves showed toxicity symptoms such as black necrotic spots. Nable et al. (1997) reported that under toxic B supply roots had adequate $B$ concentrations in comparison to the toxic $\mathrm{B}$ concentrations in the shoots.

\section{Effects on absorption of foliar-applied B}

Plants with no ${ }^{11} \mathrm{~B}$ supply experienced a significant reduction of foliar ${ }^{10} \mathrm{~B}$ absorption as compared to plants grown under $10 \mu M{ }^{11} \mathrm{~B}, 30 \mu M{ }^{11} \mathrm{~B}$ and $100 \mu M^{11} \mathrm{~B}$ (Fig. 3b). The absorption of ${ }^{10} \mathrm{~B}$ was about thrice higher in all treatments in comparison to the $0 \mu M^{11} \mathrm{~B}$ treatment. This strong decrease in foliar ${ }^{10} \mathrm{~B}$ absorption under $\mathrm{B}$-deficiency is rather unexpected and deserves further attention. Foliar absorption is driven by a concentration gradient across the leaf surface and modulated by the permeability of the leaf surface. In theory, a higher B concentration gradient after foliar B application could be expected in B-deficient versus B-sufficient leaves. However, lower ${ }^{10} \mathrm{~B}$ penetration rates were determined in $\mathrm{B}$ deficient plants. The limited rate of ${ }^{10} \mathrm{~B}$ absorption by $\mathrm{B}$-deficient leaves must be most likely caused by a reduced permeability of the leaf surface. In leaves of plants grown without ${ }^{11} \mathrm{~B}$ supply, stomata were shrunken and closed, which was earlier reported to reduce absorption of foliarapplied solutes via the stomatal pathway (Eichert and Burkhardt 2001; Eichert and Goldbach 2008). Additionally, with closed stomata, less transpiration water was released which otherwise may have recondensated on the leaf surface (Burkhardt et al. 1999) and kept foliar-applied solutes partly dissolved and mobile even though the surrounding bulk atmosphere was dry (see below). Possibly, B deficiency also induced alterations in cuticular 
structure, as was recently reported for Fe deficiency in peach and pear trees (Fernández et al. 2008). The alteration in leaf structure due to nutrient deficiencies may limit the efficiency of foliar fertilization.

The addition of polyols increased the absorption of foliar-applied B in all treatments. Generally, polyols could enhance $B$ absorption by lowering the deliquescence humidity (DRH) of the deposited substances. This would extend the period of time during which foliar-applied B is mobile and can be absorbed, if $\mathrm{RH}$ of the air is above the DRH of the mixture of components (Fernandez and Eichert 2009). The RH during the experiment was $60 \%$, which is well below the DRHs of the components, and accordingly this humectant effect should not have affected absorption. However, it has to be taken into account that leaf surfaces are surrounded by a laminar layer in which RH is higher than ambient RH (Burkhardt and Eiden 1994). As already mentioned above, water transpired by the leaves may substantially contribute to an increase in humidity, and therefore the humectant effect of polyols could have increased $\mathrm{B}$ absorption despite the low ambient $\mathrm{RH}$. This argument may also explain why polyols did not affect $\mathrm{B}$ absorption in plants without B supply because B deficiency induced stomatal closure which probably reduced the amount of water released by the leaves.

\section{Effects on B mobility}

The absolute percentage of foliar-applied ${ }^{10} \mathrm{~B}$ that moved out of the treated leaf parts ranged from 1.1 to $2.8 \%$ of the applied dose, and the effect of ${ }^{11} \mathrm{~B}$ preculture on absolute ${ }^{10} \mathrm{~B}$ mobility was similar to that on ${ }^{10} \mathrm{~B}$ absorption, i.e. the lowest amount of ${ }^{10} \mathrm{~B}$ moving out of the treated leaf parts was found in plants pretreated without ${ }^{11} \mathrm{~B}$ supply. Polyols also significantly affected ${ }^{10} \mathrm{~B}$ mobility, and overall lowest translocation was observed after the addition of sorbitol (Fig. 3c), even though the absolute absorption rate in this treatment was significantly higher than with pure BA (Fig. 3a). This might be due to the occurrence of many leaf necrotic spots in this treatment, which could have fixed ${ }^{10} \mathrm{~B}$ in the dead tissues, thus preventing its translocation.

To gain further mechanistic insight into the effects of the ${ }^{11} \mathrm{~B}$ status of plants and added polyols on ${ }^{10} \mathrm{~B}$ mobility, we calculated the shares of translocated ${ }^{10} \mathrm{~B}$ in relation to the amount absorbed by the leaf. Highest relative translocation rates were observed in plants pre-cultured in $0 \mu M^{11} \mathrm{~B}$ or $100 \mu M$ ${ }^{11} \mathrm{~B}$ (Fig. 3f, h). While high translocation rates in plants with high ${ }^{11} \mathrm{~B}$ contents can be explained by the saturation of possible $\mathrm{B}$ binding sites in the cell wall leaving more free $B$ for translocation, the reason for the relatively high shares of translocated ${ }^{10} \mathrm{~B}$ in plants without ${ }^{11} \mathrm{~B}$ supply is less obvious.

We found evidence that in this treatment stomata were disturbed and, like in plants growing under $100 \mu M^{11} \mathrm{~B}$, leaves sustained higher water potentials than plants cultivated under $10 \mu M^{11} \mathrm{~B}$ or $30 \mu M^{11} \mathrm{~B}$ indicating that both under $\mathrm{B}$ deficiency and high $\mathrm{B}$ supply the average transpiration rates were probably lower than under adequate supply, as it was reported by Eichert et al. (2010) for Fe deficient peach leaves. According to results obtained with Ricinus communis L., low transpiration rates may enhance phloem mobility of foliar-applied B (Eichert and Goldbach 2010), and possibly this was also the case in the present study with soybean.

Both polyols reduced the relative $B$ mobility as compared to the application of BA alone. This may be due to the conversion of small uncharged BA molecules into relatively large, negatively charged B-polyol complexes. While BA is moderately plasmalemma-permeable and may thus easily diffuse into the phloem, the large ionic complexes are probably rather excluded from passive transmembrane transport reducing phloem mobility. This is in contrast to the situation in plants with natural polyol-assisted B mobility, where complexation takes place not until BA has entered the phloem.

\section{Conclusion}

The results of this study indicate that $\mathrm{B}$ deficiency symptoms may reduce B absorption through the leaf surface. From an agronomic point of view this negative feedback loop may limit the chance to alleviate $\mathrm{B}$ deficiency by foliar fertilization, and it can be concluded that B should therefore be applied before severe deficiency symptoms may occur. The application of B as B-sorbitol complex proved to increase absorption but reduced within-plant B mobility. Therefore, humectants that may have the same positive effect on B absorption as sorbitol, but that may not hinder B mobility should be selected in future research attempts. 
Acknowledgements The authors acknowledge the German Research Foundation (DFG, SFB 564, TP 3.2) for financial support.

\section{References}

Akaike H (1974) New look at the statistical model identification. IEEE Trans Automat Contr AC 19:716-723

Alpaslan M, Gunes A (2001) Interactive effects of boron and salinity stress on the growth, membrane permeability and mineral composition of tomato and cucumber plants. Plant Soil $236: 123-128$

Bieleski RL (2005) Taxonomic patterns in the distribution of polyols within the proteaceae. Aust J Bot 53:205-217

Bieleski RL (1982) Sugar alcohols. In: Loewus A, Tanner W (eds) Encyclopedia of plant physiology NS Vol. 13A. Plant Carbohydrates. I. Intracellular carbohydrates. Springer, Berlin, pp 158-192

Blevins DG, Lukaszewski KM (1998) Boron in plant structure and function. Annu Rev Plant Physiol Plant Mol Biol $49: 481-500$

Brown PH, Hu H (1996) Phloem mobility of boron is species dependent: evidence for phloem mobility in sorbitol-rich species. Ann Bot 77:497-506

Brown PH, Shelp B (1997) Boron mobility in plants. Plant Soil 193:85-101

Brown PH, Bellaloui N, Hu HN, Dandekar A (1999) Transgenically enhanced sorbitol synthesis facilitates phloem boron transport and increases tolerance of tobacco to boron deficiency. Plant Physiol 119:17-20

Burkhardt J, Eiden R (1994) Thin water films on coniferous needles. Atmos Environ 28:2001-2011

Burkhardt J, Kaiser H, Goldbach H, Kappen L (1999) Measurements of electrical leaf surface conductance reveal re-condensation of transpired water vapour on leaf surfaces. Plant Cell Environ 22:189-196

Cakmak I, Römheld V (1997) Boron deficiency-induced impairments of cellular functions in plants. Plant Soil 193:71-83

Cakmak I, Kurz H, Marschner H (1995) Short-term effects of boron, germanium and high light intensity on membrane permeability in boron deficient leaves of sunflower. Physiol Plant 95:11-18

Delgado A, Benlloch M, Fernandez Escobar R (1994) Mobilization of boron in olive trees during flowering and fruit development. Hortic Sci 29:616-618

Dell B, Huang L (1997) Physiological response of plants to low boron. Plant Soil 193:103-120

Eichert T, Burkhardt J (2001) Quantification of stomatal uptake of ionic solutes using a new model system. J Exp Bot 52:771-781

Eichert T, Goldbach HE (2008) Equivalent pore radii of hydrophilic foliar uptake routes in stomatous and astomatous leaf surfaces - further evidence for a stomatal pathway. Physiol Plant 132:491-502

Eichert T, Goldbach HE (2010) Transpiration rate affects the mobility of foliar-applied boron in Ricinus communis $\mathrm{L}$ cv. Impala. Plant Soil 328:165-174

Eichert T, Peguero-Pina JJ, Gil-Pelegrin E, Heredia A, Fernandez V (2010) Effects of iron chlorosis and iron resupply on leaf xylem architecture, water relations, gas exchange and stomatal performance of field-grown peach (Prunus persica). Physiol Plant 138:48-59

Fernandez V, Eichert T (2009) Uptake of hydrophilic solutes through plant leaves: current state of knowledge and perspectives of foliar fertilization. Crit Rev Plant Sci 28:36 68

Fernández V, Eichert T, Del Rio V, Lopez-Casado G, HerediaGuerrero JA, Abadia A, Heredia A, Abadia J (2008) Leaf structural changes associated with iron deficiency chlorosis in field-grown pear and peach: physiological implications. Plant Soil 311:161-172

Hu H, Brown PH (1997) Absorption of boron by plant roots. Plant Soil 193:49-58

Khayyat M, Tafazoli E, Eshghi S, Rajaee S (2007) Effect of nitrogen, boron, potassium and zinc sprays on yield and fruit quality of date palm. Am Eurasian J Agric Environ Sci 2:289-296

Lehto T, Räisänen M, Lavola A, Julkunen-Tiitto R, Aphalo PJ (2004) Boron mobility in deciduous forest trees in relation to their polyols. New Phytol 163:333-339

Marentes E, Shelp BJ, Vanderpool RA, Spiers GA (1997) Retranslocation of boron in broccoli and lupin during early reproductive growth. Physiol Plant 100:389-399

Marschner H (1995) Mineral Nutrition of Higher Plants. Academic, London

Miwa K, Takano J, Fujiwara T (2006) Improvement of seed yields under boron-limiting conditions through overexpression of BOR1, a boron transporter for xylem loading, in Arabidopsis thaliana. Plant J 46:1084-1091

Nable RO, Banuelos GS, Paull JG (1997) Boron toxicity. Plant Soil 193:181-198

Oosterhuis DM, Zhao D (2001) Effect of boron deficiency on the growth and carbohydrate metabolism of cotton. Plant Nutr 92(Symposium 2):166-167

Papadakis IE, Dimassi KN, Bosabalidis AM, Therios IN, Patakas A, Giannakoula A (2004) Boron toxicity in 'Clementine' mandarin plants grafted on two rootstocks. Plant Sci 166:539-547

Pfeffer H, Dannel F, Römheld V (2001) Boron compartmentation in roots of sunflower plants of different boron status: A study using the stable isotopes $10 \mathrm{~B}$ and $11 \mathrm{~B}$ adoping two independant approaches. Physiol Plantarum 133:346-351

Poss JA, Grattan SR, Grieve CM, Shannon MC (1999) Characterization of leaf boron injury in salt-stressed Eucalyptus by image analysis. Plant Soil 206:237-245

Rosolem CA, Leite VM (2007) Coffee leaf and stem anatomy under boron deficiency. R Bras Ci Solo 31:477-483

Roygrong S (2009) Role of Boron and Zinc in Growth and Flowering of Lychee (Litchi chinensis Sonn.). Dissertation, University of Hohenheim

Schlegel TK, Schönherr J, Schreiber L (2005) Size selectivity of aqueous pores in stomatous cuticles of Vicia faba leaves. Planta 221:648-655

Scholander PF, Hammel HT, Bradstre ED, Hemmings (1965) Sap pressure in vascular plants. negative hydrostatic pressure can be measured in plants. Science 148:339-346

Schon M, Blevins D (1990) Foliar boron applications increase the final number of branches and pods on branches of field-grown soybeans. Plant Physiol 92:602-607

Sharma CP, Sharma PN (1987) Mineral nutrient deficiencies affect plant water relations. J Plant Nutr 10:1637-1643 
Shelp BJ, Marentes E, Kitheka AM, Vivekanandan P (1995) Boron mobility in plants. Physiol Plant 94:356-361

Shelp BJ, Kitheka AM, Vanderpool RA, Van Cauwenberghe OR, Spiers GA (1998) Xylem-to-phloem transfer of boron in broccoli and lupin during early reproductive growth. Physiol Plant 104:533-540

Sheng O, Song SW, Peng S, Deng XX (2009) The effects of low boron on growth, gas exchange, boron concentration and distribution of 'Newhall' navel orange (Citrus sinensis Osb.) plants grafted on two rootstocks. Sci Hort 121:278283
Shorrocks VM (1997) The occurrence and correction of boron deficiency. Plant Soil 193:121-148

Sotiropoulos TE, Therios IN, Dimassi KN, Bosabalidis A, Kofidis $\mathrm{G}$ (2002) Nutritional status, growth, $\mathrm{CO}_{2}$ assimilation, and leaf anatomical responses in two kiwifruit species under boron toxicity. J Plant Nutr 25:1249-1261

Warrington K (1923) The effect of boric acid and borax on the broad bean and certain other plants. Ann Bot 27:629-673

Wojcik P, Cieslinski G, Mika A (1999) Apple yield and fruit quality as influenced by boron applications. J Plant Nutr 22(9): $1365-1377$ 